\title{
Segurança, controle e monitoramento versus direitos fundamentais: Uma análise do projeto de lei “Marco Civil da Internet"
}

Jorge Alberto Silva Machado Alcimar Queiroz $^{2}$

${ }^{1}$ Grupo de Pesquisa em Políticas Públicas para o Acesso à Informação (GPOPAl). Universidade de São Paulo.
$\begin{array}{ll}\text { Correspondência: } & \text { E-mail: machado@usp.br } \\ & \text { Av. Arlindo Béttio, 1000 } \\ & \text { São Paulo-SP-Brasil } \\ & \text { CEP 03828-000 }\end{array}$

${ }^{2}$ Faculdade de Educação da Universidade de São Paulo. Instituto Universitário de Lisboa (Portugal). Universidade do Texas (EUA).

Correspondência: E-mail: asqz.usp@gmail.com

Resumo O Ministério da Justiça realizou uma consulta pública e formulou um projeto de lei para o estabelecimento de um quadro jurídico baseado em direitos civis para o uso da internet. O objetivo principal é criar uma estrutura de direitos e responsabilidades para o uso da web, bem como as condições para fornecer acesso a dados privados armazenados pelos provedores de conteúdos da internet. Com essa lei, espera-se melhorar a resolução de conflitos relacionados com privacidade e a liberdade de expressão na internet, garantindo direitos fundamentais, ao invés de criminalizar práticas sociais disseminadas ou restringir direitos.

Palavras-chave: internet, direitos civis, controles, privacidade, liberdade de expressão.

Abstract The Brazilian Ministry of Justice started an initiative for the establishment of a civil-rights based legal framework for the use of the internet. The main goal is to structure rights and responsibilities for using the web, as well as the conditions to provide access to private data. This law is expected to help solve conflicts related to privacy and freedom of expression in internet by guaranteeing fundamental rights, as opposed to criminalizing or restricting rights.

Keywords: internet, civil rights, regulatory aspects, privacy, freedom of expression.

Resumen El Ministerio de la Justicia brasileño condujo una consulta pública y 
formuló un proyecto de ley para el estabelecimiento de un cuadro jurídico basado en derechos civiles para el uso de la internet. El objetivo principal es crear una estructura de derechos y responsabilidades para el uso de la web, así como las condiciones para fornecer acceso a los datos privados almacenados por los proveedores de contenidos del internet. Con esa ley, es esperado mejorar la resolución de conflictos relacionados con privacidad y libertad de expresión en internet, garantizando derechos fundamentales, en lugar de criminalizar las prácticas sociales diseminadas 0 restringir derechos.

Palabras-clave: internet, derechos civiles, controles, privacidad, libertad de expresión. 


\section{Introdução}

Sob muitos aspectos, o comportamento dos usuários de internet é incompatível com as leis vigentes. Isso por que a legislação que se aplica a ela não foi desenhada segundo às práticas sociais, técnicas e as exigências dos usuários de internet.

Um exemplo disso é fato do "novo" código civil ignorar completamente a internet. Outro exemplo é a Lei de Direitos Autorais (de 1998), que criminaliza práticas banais de reprodução de conteúdos, necessárias para a própria rede funcione.

Em função do vazio jurídico, o judiciário brasileiro tem tomado decisões controversas que, direta ou indiretamente, afetam os direitos fundamentais, gerando censura e frequentes remoções de conteúdos por parte de provedores, muitas vezes legalmente disponibilizados.

Por outro lado, na ausência de mecanismos mais eficazes para cumprimento da lei no ambiente digital, já foram propostas bastante invasivas para monitoramento e controle da internet, como a proposta de lei 84 de 1999 (conhecido como "Al5 digital") do então senador Eduardo Azeredo, aprovado em 2012, com significativas supressões.

No âmbito internacional viu-se o Anti-Counterfeiting Trade Agreement (ACTA), bloqueado na Europa, além dos projetos de lei dos Estados Unidos da América rejeitados como o Stop Online Piracy Act (SOPA) e Protect Intellectual Property Act (PIPA). Essas iniciativas implicaram em risco severo às liberdades civis como privacidade, direito à comunicação e livre manifestação do pensamento.

O SOPA e o PIPA foram projetos da lei que tramitaram no Congresso dos Estados Unidos da América, mas acabaram sendo retirados por seus proponentes devido aos protestos (SOPA 2012, PIPA 2012).

Já o ACTA trata-se de um acordo comercial anticontrafação, assinado por uma dezena de países, muito crítica por ter sido negociado secretamente, por isso acabou sendo barrado na União Europeia e sua adesão sequer foi discutidas em muitos países. Como ponto comum, essas três iniciativas propõem ações muito invasivas para combater violações de propriedade intelectual (ACTA 2011).

Para enfrentar o desafio de criar uma regulação equilibrada da internet, o Ministério da Justiça desenvolveu um processo colaborativo para a criação de um marco de direitos civis para o uso da internet, projeto desenvolvido em parceria entre o Ministério da Justiça do Brasil e a Fundação Getúlio Vargas.

O objetivo principal foi de garantir uma estrutura de direitos e responsabilidades dirigida à web, de modo de regular os conflitos relacionados à privacidade e à liberdade de expressão na internet sem criminalizar ou restringir direitos, mas 
pela garantia dos direitos fundamentais estabelecidos pela Constituição (Marco Civil 2010).

Este debate foi estruturado em duas fases de 45 dias. A primeira fase foi baseada na seleção de questões fundamentais como a privacidade, a liberdade de expressão, neutralidade da rede, armazenamento de toras, responsabilidades legais e as diretrizes do governo.

Durante este período, a consulta pública acolheu mais de 822 contribuições da sociedade civil, bem como em relatórios oficiais de instituições públicas, privadas e organizações da sociedade civil sobre os temas relacionados.

A segunda fase - terminada em 30 de maio de 2010 - começou com a publicação do projeto completo de lei. Nesta fase foram obtidas outras 1.168 contribuições. O documento final foi apresentado, como projeto de lei 2116 de 2011 ao Congresso Nacional.

Em muitos países, tem havido pressão para a regulamentação da internet com propostas para aumentar a censura e o controle, desrespeitando a privacidade e os direitos dos cidadãos.

A proposta do governo brasileiro tem o mérito de considerar como princípio o acesso à internet como um direito civil, sendo fundamental para o exercício da cidadania, assim como a liberdade de expressão e o acesso à informação. Por isso, concentra-se na garantia de direitos, considerando as particularidades técnicas e sociais da informação no ambiente digital.

É uma lei que pode criar uma salvaguarda para sites, uma vez que evita a remoção de conteúdos da internet sem uma ordem judicial. A proposta também prevê a introdução de limites para o armazenamento e utilização de dados pessoais. Ambos os aspectos são vistos como pilares da protecção da privacidade e liberdade de expressão.

Este artigo apresenta e análise os principais aspectos do projeto brasileiro, como as questões controversas são geridas, destacando suas inovações e limitações.

\section{Situação atual no Brasil}

\section{Liberdade de expressão e privacidade}

Nos últimos anos, tem havido uma série de iniciativas relacionadas com a censura no Brasil. Em janeiro de 2010, o Tribunal de Justiça de São Paulo ordenou que fosse bloqueado o acesso ao YouTube para todos os usuários brasileiros, seguindo as exigências feitas por uma modelo famosa insatisfeita com um vídeo 
feito por um paparazzi (UOL Tecnologia 2007) em um local público. Esta medida foi a causa de intensa discussão nos meios de comunicação. A ordem foi cancelada dois dias depois, após muitas e protestos dos usuários de internet.

De acordo com a ONG Artigo 19, mais processos são feitos contra jornalistas no Brasil do que em qualquer outro país. São 3.133 processos contra 3.237 jornalistas (Conjur 2007a, 2007b).

Não há estatísticas confiáveis sobre a censura, mas existem inúmeros casos de pressão jurídica sobre bloggers, resultando em um clima de medo na chamada blogosfera. No Brasil, este é um problema tão frequente que os ciberativistas se referem a ele como "blog bullying". A maioria dos casos envolve a expressão de opiniões negativas ou reclamações sobre empresas, serviços ou políticos (WikiPP 2010).

Não há muitos dados sobre as requisições judicais ou extrajudiciais que afetam a privacidade de usuários ou as comunicações de organizações. Um exemplo disso é que, entre 1ㅇ. de julho de 2009 e 31 de dezembro de 2009, as autoridades brasileiras fizeram 3.663 pedidos de remoção de dados do Google e YouTube.

Isso deixou o Brasil em primeiro lugar no ranking mundial da Google (Google 2010), seguido por EUA (3.580) e Reino Unido (1166). O Brasil também ocupa o primeiro lugar no que se refere ao pedido de remoção de conteúdos, com 291 solicitações, seguido pela Alemanha, com 188.

\section{Violação de direitos autorais}

Um estudo realizado em 2009 por Barbosa e Craveiro (2010) indicou que houve 298.181 denúncias de incidentes de segurança para o Comitê Gestor da Internet no Brasil (CGI) entre janeiro e junho de 2009. Destes, 233.604 casos foram classificados como "fraudes".

Analisando os detalhes dessa classificação, o estudo mostra que cerca de 217 mil registros estão relacionados com a violação de direitos autorais. A literatura acadêmica da área de segurança da informação não considera violação de direitos autorais como uma espécie de ataque de segurança em sistemas; dividindo os ataques à segurança dos sistemas em campos do tipo: de autenticação com a identidade de usuários ou de base de dados; limites de controle de acesso e controle de acesso ao sistema e aplicativos conectados por meio de transferência de dados; à confidencialidade de dados, tanto em virtude da ligação, campo selecionado ou o fluxo do trânsito; à integridade dos dados, que garante que os dados recebidos são os mesmos que os do emissor; nãorepúdio permitindo não-negação tanto de origem como de destino; à disponibilidade de serviço, que garante que um sistema ou aplicação será acessível e utilizável quando solicitado (Stallings 2007). 
Assim, "violação de direitos autorais" foi responsável por 96,06\% de todas as fraudes no primeiro semestre de 2009. As denúncias foram feitas aparentemente por uma única entidade, a Associação Antipirataria de Cinema e Música (APCM). Trata-se de uma organização lobista privada ligada à MPA (Motion Picture Association) e à IFPI (International Federation of Phonographic Industry).

Através da pressão de seus advogados, a APCM moveu milhares de páginas e links para sites e blogs. O medo de enfrentar processos judiciais resultou na remoção completa de blogs e sites de usuários da internet, mesmo quando o conteúdo removido não tem problemas de licença. No primeiro semestre de 2009, a APCM anunciou a remoção de 118.750 links de filmes e música, de 22.113 posts em blogs e 20.332 links para arquivos P2P (APCM 2010).

Embora isso tenha afetado as comunicações, o resultado é insatisfatório porque os links podem ser substituídos e facilmente encontrados em redes de compartilhamento do tipo P2P, onde há comunicação pode ser anonimizada. Há também o uso generalizado de serviços de download e upload de arquivos como o RapidShare ou Mega.

Fraudes e pedofilia

O combate de fraudes e pedofilia é o principal argumento usado no Brasil para defender o armazenamento de registros de logs de provedores de acesso à internet ou de conteúdos.

O lobby pró-monitoramento mais ativo vem da Federação Brasileira de Bancos (FEBRABAN), que afirma que seus associados tem muitas com a fraude - sem apresentar números. No entanto, os bancos brasileiros não usam sistemas de segurança, como chaves criptográficas.

A implementação de serviços mais avançados pode custar muito mais do que fazer lobby a favor da proposta de uma lei que determina o controle sobre a internet.

O setor bancário deu forte apoio ao "projeto Azeredo" (CPD 2006), cujo teor gerou vários protestos e campanhas por parte da sociedade civil. Em março de 2009, o governo federal, com maioria no Congresso e no Senado, foi pressionado a tomar a decisão política de bloquear temporariamente a proposta. O efeito positivo desse processo foi promover a discussão que levou à formulação do Marco Civil da Internet brasileiro.

Por outro lado, há uma discussão sobre se a lei permite a utilização da chave criptográfica, porque a Constituição garante a liberdade de expressão, mas veda o anonimato.

Quanto o argumento do combate à pedofilia para justificar o monitoramento 
sobre os usuários da rede, o principal proponente aparentemente é uma ONG SaferNet no Brasil. A ONG, possuidora de um banco de imagens de pedofilia, assedia os políticos e autoridades governamentais para uma legislação mais dura sobre os usuários de internet, assim como a implementação políticas mais restritivas no ambiente digital.

A SaferNet promoveu audiência pública com o Ministério Público (MPF 2010, Machado 2009) para convencer os juízes e autoridades da importância da aplicação da política de retenção de dados de logs. É interessante notar que o "lobby da pedofilia" tem vindo a trabalhar em conjunto com o lobby bancário para melhorar os controles sobre a internet.

O estado atual da aplicação da lei no Brasil é caracterizado pela incerteza. No Código Civil Brasileiro, reformado em 2003, não há nenhuma referência à internet, cuja regulação se dá básica de forma indireta, segundo o entendimento dado pelos juízes. Estes, por sua vez, carecem de conhecimentos e referências técnicas e, portanto, têm de tomar decisões com base em interpretações muito subjetivas de leis defasadas.

\section{Temas-chave na proposta governamental}

Embora o projeto de lei vise alcançar uma relação harmoniosa entre os provedores de conexão, prestadores de serviços, diferentes tipos de usuário e autoridade pública, ele está profundamento focado na garantia dos direitos e liberdades civis.

O artigo $2^{\circ}$ determina que a regulamentação da internet no Brasil deve ser fundamentada no reconhecimento da natureza internacional da internet, os direitos de cidadania no ambiente digital; dos direitos humanos, os valores da pluralidade, diversidade, abertura, colaboração, assim como a livre iniciativa, liberdade de concorrência e direitos do consumidor. No artigo 3 o lista os princípios do uso da internet no Brasil:

1. Garantia da liberdade de expressão, comunicação e manifestação de pensamento, nos termos da Constituição;

II. Proteção da privacidade;

III. Proteção aos dados pessoais, na forma da lei;

IV. Preservação e garantia da neutralidade da rede, conforme regulamentação;

V. Preservação da estabilidade, segurança e funcionalidade da rede, por 
meio de medidas técnicas compatíveis com os padrões internacionais e pelo estímulo ao uso de boas práticas;

VI. Responsabilização dos agentes de acordo com suas atividades, nos termos da lei;

VII. Preservação da natureza participativa da rede.

Apesar do texto bem escrito e da abordagem moderna, a lei tem pontos extremamente polêmicos, como dos que tratam do armazenamento de registros de conexão, dos tipos de dados que podem ser armazenados e por qual período de tempo, dos mecanismos de remoção de conteúdo de sites, do papel dos provedores de conexão e dos prestadores de serviços na vigilância da rede (Quadro 1).

Essas discussões são diretamente afetadas pelas diferentes interpretações sobre o alcance e os limites da liberdade de expressão, bem como sobre o equilíbrio que deve haver entre o acesso à informação e cultura e os direitos de propriedade intelectual no ambiente digital.

Este cenário coloca em lados diferentes, a indústria cultural, agências de segurança, grupos religiosos, policias civis e federal e, de outro, organizações de defesa da liberdade de expressão, direito à comunicação, direitos do consumidor, direitos humanos e usuários de internet. 
Quadro 1. Principais aspectos do Marco Civil da Internet. Brasília, 1999.

\begin{tabular}{|c|c|}
\hline Tema & Abordagem dada \\
\hline Responsabilidade & Obrigação de manter os registros não pode ser transferida a terceiros \\
\hline Divulgação de logs de conexão & Somente com ordem judicial ou com permissão por escrito do usuário \\
\hline Divulgação dos registros do usuário & Somente com ordem judicial \\
\hline $\begin{array}{l}\text { Cruzamento dos dados de conexão com } \\
\text { os de serviço }\end{array}$ & Só pode ser feito com ordem judicial \\
\hline
\end{tabular}


Tema

Procedimentos legais para remoção de conteúdos

\section{Abordagem dada}

(continuação)

\section{A notificação judicial deverá conter, sob pena de nulidade:}

a) Identificação do requerente, incluindo nome completo, registro civil e números de identificação fiscal e informações de contato;

b) Data e hora da transmissão;

c) Identificação clara e específica do conteúdo sinalizado como prejudicial para permitir localização inequívoca do material notificado;

d) Descrição da relação entre o requerente e o conteúdo identificado como prejudicial; e

e) Justificativa legal para a remoção.

Procedimentos para pedidos judiciais de registros

requerimento ao juiz deve ser fundado por indícios de ocorrência de ilícito, com justificativa motivada da utilidade dos registros solicitados para fins de investigação ou instrução probatória e período ao qual se referem os registros. O juiz é responsável por garantir o sigilo das comunicações e para preservar a intimidade, a imagem de privacidade, honra e usuário, sendo capaz de determinar se as informações devem ser mantidas sob sigilo nos registros do tribunal. A autoridade policial ou administrativa poderá requerer ao juiz cautelarmente a guarda de registros de conexão por até 60 dias.

Neutralidade da rede

- responsável pela transmissão, comutação ou roteamento tem o dever de tratar de forma isonômica quaisquer pacotes de dados, sem distinção por conteúdo, origem e destino, servico, terminal ou aplicativo, sendo vedada qualquer discriminação ou degradação do tráfego que não decorra de requisitos técnicos necessários à prestação adequada dos serviços, conforme regulamentação (a neutralidade será regula posteriormente).

$\begin{aligned} & \text { Proteção da privacidade das } \\ & \text { comunicações na internet }\end{aligned}$
$\begin{aligned} & \text { Inviolabilidade e ao sigilo de suas comunicações pela internet, salvo por ordem } \\ & \text { judicial, nas hipóteses e na forma que a lei estabelecer para fins de investigação } \\ & \text { criminal ou instrução processual penal. }\end{aligned}$

Fonte: Autoria própria. 


\section{Respostas e propostas de alteração ao projeto de texto: Interesses conflitantes}

O projeto de lei recebeu inúmeras contribuições e críticas. A seguir, analisamos o mais importante, concentrando nossa análise sobre os temas-chave e o papel desempenhado pelos atores principais.

Muitas entidades envolvidas na proteção da propriedade intelectual e, portanto, interessadas em mais regulação e controles sobre a internet, enviaram suas propostas, como Aliança Internacional de Propriedade Intelectual (IIPA), Federação Internacional da Indústria Fonográfica (IFPI), Associação Brasileira de Produtores de Discos (ABPD), Motion Picture Association of America (MPAA), Entertainment Software Association (ESA), Federação Ibero-Latino-Americana de Performers (FILAIE), Associação Mexicana de Fonograma e Videograma (AMPROFON), câmara de fonogramas e de videogramas de produtores argentinos (CAPIF), Sociedade de Autores e Compositores do México (SACM), União Brasileira de Filmes (UBV), bem como uma série de escritórios de advocacia.

Dado que o Brasil é um dos maiores mercados mundiais da música, filmes, software e da indústria do entretenimento em geral, houve uma grande manifestação das organizações que atuam junto à indústria cultural e de "intermediários" na distribuição de conteúdos.

A MPAA chama a atenção para a necessidade de criação de "um regime de responsabilidade indireta que incentive os provedores de internet a cooperar com os titulares de direitos no combate à atividades ilegais online". MPAA quer que isso seja feito:

[com] as ferramentas de gerenciamento de rede, incluindo 0 reconhecimento conteúdo tecnológico", usando "as medidas cautelares e liminares" contra as violações dos direitos de propriedade intelectual, e permitindo que a informação a ser obtida sobre os registros de acesso a serviços de internet sem a autorização expressa dos usuários através dos tribunais, incluindo injunções (MPAA 2010).

Em outras palavras, defendem o uso de ferramentas de monitoramento de tráfego, o armazemento de registros dos usuários e a responbilização dos provedores de internet, que deveriam atuar como "vigilantes do conteúdo".

A IIPA é mais rigorosa sobre as restrições legais que devem ser impostas aos usuários de internet. A entidade é composta por sete federações filiadas: a Association of American Publishers (AAP), a Business Software Alliance (BSA), a Entertainment Software Association (ESA), a Film \& Television Alliance 
Independent (IFTA), a Motion Picture Association of America (MPAA), a National Music Producers Association (NMPA) e a Recording Industry Association of America (RIAA).

De acordo com a IIPA, as sete associações representam mais de 1.900 empresas norte-americanas que produzem e distribuem materiais protegidos por direitos autorais em todo o mundo. Isso inclui todos os tipos de software de computador, incluindo software aplicativos de negócios e software de entretenimento (como os discos e cartuchos de videogame, computadores pessoais, CD-ROMs e outros produtos multimídia); filmes teatrais, programas de televisão, DVDs e home vídeo e representações digitais de obras audiovisuais, música, discos, CDs e fitas cassetes e livros didáticos, livros comerciais, publicações e revistas de referência e profissional (IIPA 2010a).

A IIPA crítica fortemente os direitos propostos no projeto de lei. Buscando "melhorar a proteção internacional dos direitos autorais", a entidade afirma que:

os elementos do projeto de lei eliminam os incentivos para a cooperação entre os titulares de direitos e Provedores de Serviços de Internet, podendo inibir o desenvolvimento de ferramentas e políticas eficazes de combate à violação online (...) e impede o uso potencial de uma variedade de mecanismos para lidar com a pirataria online (IIPA 2010b).

Mas as críticas mais detalhadas ao projeto do lei vieram da Aliança Internacional de Propriedade Intelectual (IFPA). Representando a indústria fonográfica em todo o mundo (1.400 gravadoras de 66 países), além de associações industriais afiliadas em 45 países, a IFPA tem como missão "promover o valor da música gravada, salvaguardar os direitos dos produtores de fonogramas e ampliar os usos comerciais de música gravada em todos os mercados onde os seus membros operam" (IFPA 2010a).

Sua contribuição para o projeto de lei tem três pontos principais:

i) A importância dos direitos autorais no ambiente online;

ii) A "neutralidade da rede", permitindo aos provedores de acesso à internet de discriminar entre conteúdos e serviços legais e ilegais;

iii) A necessidade de "incentivos" para provedores de serviços de internet tomarem medidas para combater a pirataria online. 
De acordo com a proposta IFPA:

assumindo que o objetivo da neutralidade é perseguido, ele não deve ser lido para eliminar a distinção vital entre conteúdos lícitos e de material ilícito (...). Isso poderia frustrar potenciais esforços voluntários por PSIS para conter o fluxo do tráfico ilegal passando por cima de suas redes. (...). A definição estabelecida no projecto de proposta [neutralidade de rede], portanto, constitui uma medida drástica, com um impacto negativo não só sobre PSIS, mas também em todas as indústrias de direitos autorais (...). Qualquer regulamentação sobre neutralidade da rede deve ser feito com cuidado, a fim de não proteger, inadvertidamente, a disseminação de conteúdo ilegal (IFPA 2010b).

O documento IFPA chama os provedores de acesso à internet de "guardiões da internet". "Eles [ISPS] devem ser devidamente incentivados a cooperar com os titulares de direitos na luta contra a violação online."

De acordo com o IFPA "muitos países adaptaram suas leis em conformidade, garantindo incentivos legais para PSIS para tomar medidas razoáveis e eficazes contra as diversas formas de pirataria". Mas a proposta IFPA não indicar qualquer país ou sistema regulatório onde isso esteja em vigor.

O IFPA argumenta que "mais e mais países estão considerando novas soluções para lidar com a pirataria online que envolve o conteúdo que não está hospedado em servidores de PSI, mas reside em computadores de usuários e é distribuído por programas peer-to-peer de compartilhamento de arquivos".

A partir disto recomenda a aplicação de "mecanismos de resposta graduada com impedimentos, sanções disponíveis contra infratores reincidentes que ignoram uma série de avisos e advertências". Em poucas palavras, defende punições diretas aos usuários, como multas ou desconexão forçada da rede, como já se tentou fazer, sem êxito, na França (Fischer 2006).

A proposta da IIPA conclui com uma crítica irônica e arrogante em relação à equipe do Ministério da Justiça, responsável pela compilação das contribuições enviadas na consulta pública e na elaboração do projeto de lei, sugerindo seu aperfeiçoamento por "especialistas em propriedade intelectual":

A abordagem do projeto de proposta deve ser repensada e alterada substancialmente com a entrada de especialistas em propriedade intelctual e o envolvimento direto das comunidades de direitos autorais para estabelecer um quadro jurídico adequado proporcionando as 
condições necessárias para os mercados legítimos se desenvolverem no ambiente online. $O$ pré-requisito central é o reconhecimento da necessidade de efetiva proteção dos direitos autorais e a capacidade de garantir ações contra condutas ilegais.

Deve-se notar que IIPA recolhe informações para o Relatório Especial 301, elaborado pelo Escritório do Representante de Comércio dos Estados Unidos, onde o Brasil estava listado na ocasião na "lista de observação" (watchlist).

De acordo com a seção 301 da Lei de Comércio de 1974, EUA podem impor sanções aos países que violam os direitos comerciais. Internacionalmente, a IIPA coloca mais pressão sobre o Brasil para enrijecer as leis de propriedade intelectual.

Além de cidadãos, organizações da sociedade civil e de organizações de defesa do consumidor enviaram suas contribuições, por exemplo, Instituto Brasileiro de Defesa do Consumidor (IDEC), PROTESTE Associação Brasileira de Defesa do Consumidor.

Em geral, as contribuições da sociedade civil visavam fortalecer os direitos civis na proposta sujeita a consulta pelo Ministério da Justiça. O único item que recebeu críticas mais severas foi a exigência que os provedores de conteúdo armazenassem os logs de seus usuários. A maioria das organizações da sociedade civil defendeu a não obrigatoriedade do armazenamento de logs.

A Polícia Federal enviou o seu contributo pedindo um aumento significativo das restrições, tais como o aumento do armazenamento de logs de conexão de dados por um período mínimo de três anos, o acesso aos dados sem ordem judicial e a proibição do uso de chaves criptográficas, entre outras medidas.

Quanto à proposta sobre o tempo de armazenamento de registro de dados, o documento da Polícia Federal é muito irônico: "ficar com esse tempo seria motivo de comemoração para o crime organizado que iria encontrar incentivo para usar a internet para a prática de suas ações ilícitas" (Polícia Federal 2010).

A Polícia Federal choca-se com as organizações de direitos civis por defender o acesso aos dados dos usuários por "autoridade policial", sem a necessidade de uma ordem judicial.

\section{Conclusão: O futuro da internet brasileira - Entre o controle e a liberdade}

Controle ou liberdade? Uma ampla gama de atores tomou uma posição pública. 
De certa forma, a consulta para o Marco Civil da Internet acabou levando a uma interessante expressão sobre microcosmo de organizações que disputam no campo da regulamentação da internet.

A consulta deixou bem claro, que são os que querem controlar a rede, orientados em interesses específicos e aqueles que querem garantir a internet como espaço de liberdades civis, tentando garantir pela regulamentação, as liberdades existentes - porém sob constante ameaça - pelo ambiente desregulado.

Tudo indica que, seja qual for a decisão a ser tomada, ela deva ser predominantemente política. Qual lado que a sociedade optará: a do direito à propriedade, do discurso do monitoramento e controle ou a das inovações sociais, políticas e técnicas pela liberdade de acesso à cultura e informação? Ironicamente, as tecnologias digitais têm grande potencial tanto para compartilhamento e monitoramento.

Não se deve esquecer que a ARPAnet (rede da Advanced Research and Projects Agency), depois renomeada internet, foi criada originalmente para ser uma rede de compartilhamento de: i) base de dados; ii) banda de transmissão e de iii) processamento de dados.

Foi seu poder de promover a inovação e a colaboração que a fez florescer e se expandir. Pela sua arquitetura de rede, censura e bloqueio são tomados como anomalias. A informação, viajando em pacotes, traça diferentes caminhos até chegar a seu destino. Aos poucos, se constituiu em uma gigantesca e descentralizada rede de compartilhamento, cuja estrutura se expandiu continuamente à medida que mais países, regiões e pessoas se conectavam.

Um dos maiores riscos atuais do marco civil se refere à "neutralidade da rede". O conceito de que a rede é neutra é muito importante para que não haja interferência e nem tratamento diferenciado nos conteúdos que nela trafegam, de modo que a haver um acesso igualitário à informação.

Essa concepção está no cerne da criação da internet. No entanto, há enorme pressão das concessionárias de serviços de telecomunicações para que a neutralidade da rede no texto do marco civil seja relativizada, de modo que as empresas de telefonia possam oferecer "serviços diferenciados".

Um exemplo disso seria cobrar para priorizar o tráfego de dados de um site em detrimento de outro. Isso significa dizer que Vivo podia cobrar da Rede Globo para que seu site carregasse rapidamente, independente do tipo de assinatura do serviço de banda larga contratados pelo usuário.

Isso levaria gradualmente ao resultado de que as grandes empresas teriam suas informações viajando em velozes "autoestradas", ao passo de os demais, não podendo pagar o pedágio, teriam seus dados trafegados com lentidão em "velhas estradas esburacadas". 
Isso prejudicaria enormemente a diversidade de conteúdos que hoje se vê na internet. Por essa razão, o lobby das concessionárias de serviços de telecomunicações tem feito pressão para o texto do marco civil aponte para que a "regulação" da neutralidade da rede seja feita pela Agência Nacional de Telecomunicações (ANATEL), instituição sob grande poder de influência das empresas de telecomunicação - e baixo controle social.

Que acontecerá com a rede se prevalecer sobre seu desenho visões meramente mercantis ou centradas no monitoramento do tráfego para combater às "violações de direito autoral"?

Quais seriam os limites aceditáveis das medidas de "segurança e controle" em detrimento dos direitos civis? Qual é o valor da liberdade de acesso à informação e cultura na nossa sociedade? Para responder a essas perguntas, temos de enfrentar um desafio claramente expresso em 2007 por Yoshai Benkler em seu livro The Wealth of Networks:

There is no guarantee that networked information technology will lead to the improvements in innovation, freedom, and justice that / suggest are possible. That is a choice we face as a society. (Benkler 2007:18)

Dependendo de como o projeto do Marco Civil da Internet resistir a alterações, ele poderá ser a base de garantias de liberdades civis consagradas - ou a base de uma sociedade vigiada e controlada.

\section{Referências}

Associação Antipirataria de Cinema e Música (APCM). APCM divulga estatísticas de pirataria na internet. 2010. Disponível na internet em: http://www.apcm.org.br/conteudo_geral.php?ID_NOT=107\&TARGET=HST [ Acesso em: mai. 2013].

Barbosa DP, Craveiro GS. Estudo técnico da legislação 89 de 2003 acerca da internet brasileira. Bauru: GPOPAl, 2010.

Benkler Y. The wealth of networks. New Haven: Yale University Press, 2007.

Brasil. Ministério da Justiça. New draft bill proposition on civil rights framework for the internet in Brazil. Brasília, 2010. Disponível na internet em: https://docs.google.com/fileview?id=0B-

a4T5EI0jxuZDcxMDMzNmItZTc5Ny00MmU4LTIIMTKtNTUyMThiOGI5MmYw\&hl= pt_BR [ Acesso em: mai. 2013]. 
Consultor Jurídico (Conjur). Brasil bate recorde mundial em ações contra jornalistas. São Paulo, 2007a. http://www.conjur.com.br/2007-out05/brasil_bate_recorde_mundial_acoes_jornalistas [ Acesso em: mai. 2013].

Consultor Jurídico (Conjur). Valor médio de indenizações contra imprensa sobe para R\$ 80 mil. São Paulo, 2007b. http://www.conjur.com.br/2007-mai31/aumenta_valor_medio_indenizacoes_imprensa [Acesso em: mai. 2013].

Centro de Processamento de Dados da Fundação Universidade Federal do Rio Grande (CPD). Projeto de Lei do Senado 76 de 2000. Brasília, 2006. Disponível na internet em: http://www.cpd.furg.br/bin/noticias/index.php?id_noticia=13 [Acesso em: mai. 2013].

Fischer K. France's legal P2P stunt may be coming to an end. ArsTechnica, 07 de março de 2006. Disponível na internet em: http://arstechnica.com/uncategorized/2006/03/6328-2/ [Acesso em: mai. 2013].

Google. Transparency reports. Government requests directed to Google and YouTube. 2010. Disponível na internet em: http://www.google.com/governmentrequests/ [ Acesso em: mai. 2013].

International Federation of the Phonographic Industry (IFPI). IFP/'s mission. 2010a Disponível na internet em: http://www.ifpi.org/content/section_about/index.html [ Acesso em: mai. 2013].

International Federation of the Phonographic Industry (IFPI). Contribuição do IFPI (EUA) para o Marco Civil da Internet. 2010b. Disponível na internet em: http://culturadigital.br/marcocivil/2010/05/26/contribuicao-do-ifpi-para-omarco-civil-da-internet/ [ Acesso em: mai. 2013].

International Intellectual Property Alliance (IIPA). Description of IIPA. 2010a. Disponível na internet em: http://www.iipa.com/aboutiipa.html [ Acesso em: mai. 2013].

International Intellectual Property Alliance (IIPA). Contribuição da IIPA (EUA). 2010b. Disponível na internet http://culturadigital.br/marcocivil/2010/05/26/contribuicao-do-iipa-para-omarco-civil-da-internet/ [ Acesso em: mai. 2013].

Machado J. Relato da audiência pública no MPF sobre armazenamento de logs. São Paulo: GPOPAl, 2009. Disponível na internet em: http://www.gpopai.usp.br/wiki/index.php/Relato_da_audi\%C3\%AAncia_p\%C3\% BAblica_no_MPF_sobre_armazenamento_de_logs [ Ácesso em: mai. 2013].

Marco Civil da Internet. Draft bill proposition on civil rights framework for internet in Brazil. 2010. Disponível na internet em: http://culturadigital.br/marcocivil/2010/04/20/draft-bill-propostion-on-civil- 
rights-framework-for-internet-in-brazil/ [ Acesso em: mai. 2013].

Motion Picture Association (MPA). Consulta pública do anteprojeto de lei sobre o Marco Civil da Internet. 2010. Disponível na internet em: http://culturadigital.br/marcocivil/2010/05/29/contribuicao-da-mpabrasil/\#more-1757 [ Acesso em: mai. 2013].

Ministério Público Federal (MPF). Chamada para audiência do MPF sobre armazenamento de logs. 2010. Disponível na internet em: http://www.gpopai.usp.br/wiki/index.php/Chamada_para_audi\%C3\%AAncia_do _MPF_sobre_armazenamento_de_logs [Acesso em: mai. 2013].

Polícia Federal. Contribuição da Polícia Federal para o Marco Civil da Internet. 2010. Disponível na internet http://culturadigital.br/marcocivil/2010/05/31/contribuicao-da-policia-federalpara-o-marco-civil-da-internet/\#more-1839 [ Acesso em: mai. 2013].

Stallings W. Cryptography and network security. $4^{\text {th }}$. ed. Englewood Cliffs: Prentice Hall, 2007.

UOL Tecnologia. Entenda o processo que levou ao bloqueio do YouTube. 2007. Disponível na internet em: http://tecnologia.uol.com.br/ultnot/2007/01/09/ult4213u7.jhtm [ Acesso em: mai. 2013].

Wiki Partido Pirata (WikiPP). Blog_Bullying. 2010. Disponível na internet em: http://wiki.partidopirata.org/Blog_Bullying [Acesso em: mai. 2012]. 